\title{
Rancang Bangun Alat Ukur Tingkat Kekeruhan Air Menggunakan Fotodioda Array Berbasis Mikrokontroler ATMega328
}

\author{
Annisa Oktaviani Putri*, Harmadi \\ Laboratorium Elektronika dan Intrumentasi, Jurusan Fisika, Universitas Andalas, Padang \\ *annisaop12@gmail.com
}

\begin{abstract}
ABSTRAK
Telah dirancang bangun alat ukur tingkat kekeruhan air menggunakan fotodioda array. Fotodioda array tersusun dari 5 buah fotodioda secara paralel. Alat ukur ini bekerja berdasarkan metode Nephelometri dengan posisi fotodioda array $90^{\circ}$ terhadap sumber cahaya. Sumber cahaya yang digunakan berasal dari LED merah dengan panjang gelombang $650 \mathrm{~nm}$. Tegangan keluaran dari fotodioda array diproses oleh mikrokontroler kemudian ditampilkan menggunakan LCD 2x16. LCD menampilkan nilai tingkat kekeruhan air dengan satuan NTU (Nephelometric Turbidity Units). Pengukuran alat ukur tingkat kekeruhan air diperoleh pada rentang 17,57 NTU sampai 189,55 NTU dengan error rata-rata alat ukur tingkat kekeruhan air yang telah dirancang yaitu sebesar 2,964\%.

Kata kunci : fotodioda array, NTU, tingkat kekeruhan air
\end{abstract}

\section{ABSTRACT}

A turbidimeter using photodiode array has been designed. Photodiode array arranged of 5 photodiodes in paralel. This turbidimeter works using Nephelometric method with photodiode array position $90^{\circ}$ to the light source. The light source is red LED with wavelength of $650 \mathrm{~nm}$. The output voltage from photodiode array processed by microcontroller then displayed in LCD 2x16. LCD displays the value of turbidity in NTU (Nephelometric Turbidity Units). The measurement ability of this meter is in the range of 17,57 NTU to 189,551 NTU with the average error measure turbidity liquid engineering is 2,964 \%. Key Words : Photodiode Array, NTU, turbidity

\section{PENDAHULUAN}

Air sungai merupakan salah satu sumber air bersih yang biasa digunakan oleh masyarakat dalam kegiatan sehari-hari. Air sungai yang sudah dicemari oleh air limbah dapat berdampak buruk bagi kesehatan masyarakat. Salah satu pengaruh air limbah yaitu bertambahnya tingkat kekeruhan air sungai. Pengkonsumsian air keruh dapat mengakibatkan timbulnya berbagai jenis penyakit seperti diare dan penyakit kulit (Paramytha, 2016).

Peraturan Menteri Kesehatan Republik Indonesia Nomor 416/MENKES/PER/IX/1990 Tanggal 3 September 1990 menjelaskan, tingkat kekeruhan air bersih yang bisa digunakan yaitu 25 NTU (Nephelometric Turbidity Unit). Tingkat kekeruhan air yang melebihi 25 NTU maka air tersebut tidak bisa digunakan dalam kegiatan sehari-hari.

Tingkat kekeruhan air biasa diukur dengan turbidimeter dalam satuan NTU (Internasional Standards Organization, 1999). Harga turbidimeter cukup mahal sehingga hanya dipakai oleh kalangan tertentu seperti PDAM (Perusahaan Daerah Air Minum), perusahaan air mineral, atau perusahaan yang membutuhkan nilai tingkat kekeruhan zat cair. Alat ukur diperlukan untuk mengukur tingkat kekeruhan air dengan harga yang lebih murah (Siltri dkk, 2015).

Penelitian yang berkaitan dengan pengukuran tingkat kekeruhan air pernah dilakukan oleh Lambrou dkk. (2008) dengan menggunakan satu fotodioda untuk mendeteksi tingkat kekeruhan air. Penelitian menghasilkan alat ukur tingkat kekeruhan air yang mendeteksi kekeruhan dari 1-100 NTU. Nuzula dan Endarko (2010) telah melakukan penelitian alat ukur tingkat kekeruhan air yang dapat mendeteksi kekeruhan dari 0-200 NTU. Maemunnur dkk. (2016) juga telah melakukan penelitian dengan pengukuran tingkat kekeruhan air dari 0-150 NTU.

Penelitian-penelitian yang telah dilakukan hanya menggunakan satu fotodioda untuk pendeteksiannya, sehingga pengukuran hanya dilakukan pada satu titik. Pengukuran tingkat kekeruhan pada satu titik akan menyebabkan alat yang dibuat kurang akurat. Tingkat kekeruhan air yang disebabkan oleh partikel-partikel terlarut dalam air akan berbeda di setiap titik, sehingga diperlukan sebuah sensor yang mampu mendeteksi tingkat kekeruhan air pada lebih dari satu titik. Sensor yang akan digunakan pada penelitian ini yaitu fotodioda array. Fotodioda 
array (PDA) biasa digunakan sebagai detektor pada metode HPLC (High Performance Liquid Chromatography) yang merupakan salah satu teknik kromatografi untuk zat cair. Fotodioda array pada HPLC mampu mengekstrak kromatogram pada panjang gelombang tertentu sehingga diperoleh informasi yang kuantitatif dan kalibrasi yang baik (Romano dkk., 2010).

Berdasarkan uraian yang telah dijelaskan, maka dilakukan penelitian untuk merancang bangun alat ukur tingkat kekeruhan air menggunakan fotodioda array. Fotodioda array digunakan agar titik pengukuran lebih dari satu sehingga alat yang dibuat lebih akurat. Hasil pengukuran yang akan diperoleh yaitu besar kekeruhan dalam satuan NTU dan akan ditampilkan pada LCD.

\section{METODE}

\subsection{Diagram Blok sistem}

Pengukuran kekeruhan air yang dilakukan membutuhkan sumber cahaya yang diarahkan ke bahan uji. Bahan uji yang digunakan yaitu air dengan tingkat kekeruhan yang berbeda. Diagram blok sistem pengukuran kekeruhan air dapat dilihat pada Gambar 1.

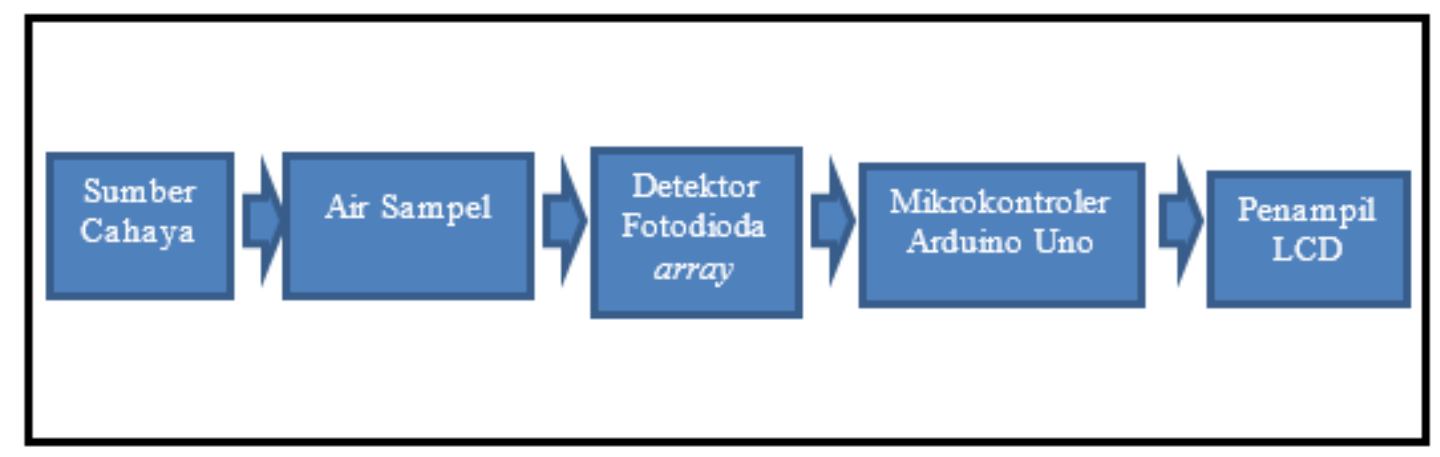

Gambar 1 Diagram blok pengukuran tingkat kekeruhan air

Sumber cahaya yang digunakan yaitu LED dengan panjang gelombang $650 \mathrm{~nm}$. Cahaya yang diarahkan dideteksi oleh fotodioda. Keluaran yang dihasilkan oleh fotodioda yaitu berupa tegangan lalu diproses oleh arduino uno sesuai dengan program yang telah di-upload. Hasil dari proses pengolahan data ditampilkan melalui LCD dengan satuan NTU.

\subsection{Rancangan Fotodioda Array}

Rangkaian fotodioda array yang dibuat memerlukan lima buah fotodioda, resistor, kapasitor, dan op-amp. Lima buah fotodioda disusun secara paralel sesuai dengan Gambar 2. Rangakaian secara paralel digunakan agar tegangan yang mengalir pada setiap rangakain sama. Lima fotodioda yang disusun secara paralel ini yang disebut sebagai fotodioda array. Keluaran yang didapatkan berupa tegangan yang dihubungkan dengan input analog pada Arduino Uno.

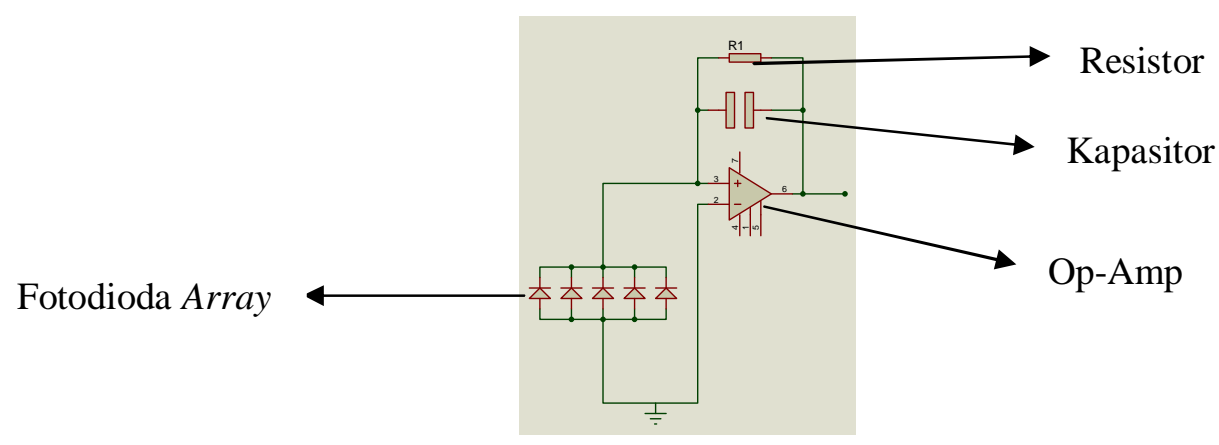

Gambar 2 Rangkaian fotodioda array 


\subsection{Rancangan Perangkat Lunak}

Sistem instrumentasi yang membutuhkan program perlu adanya urutan instruksi agar program dapat berjaan dengan baik. Program yang digunakan pada penelitian ini yaitu IDE Arduino. Perancangan perangkat lunak sistem dibuat dalam bentuk diagram alir seperti pada Gambar 3.

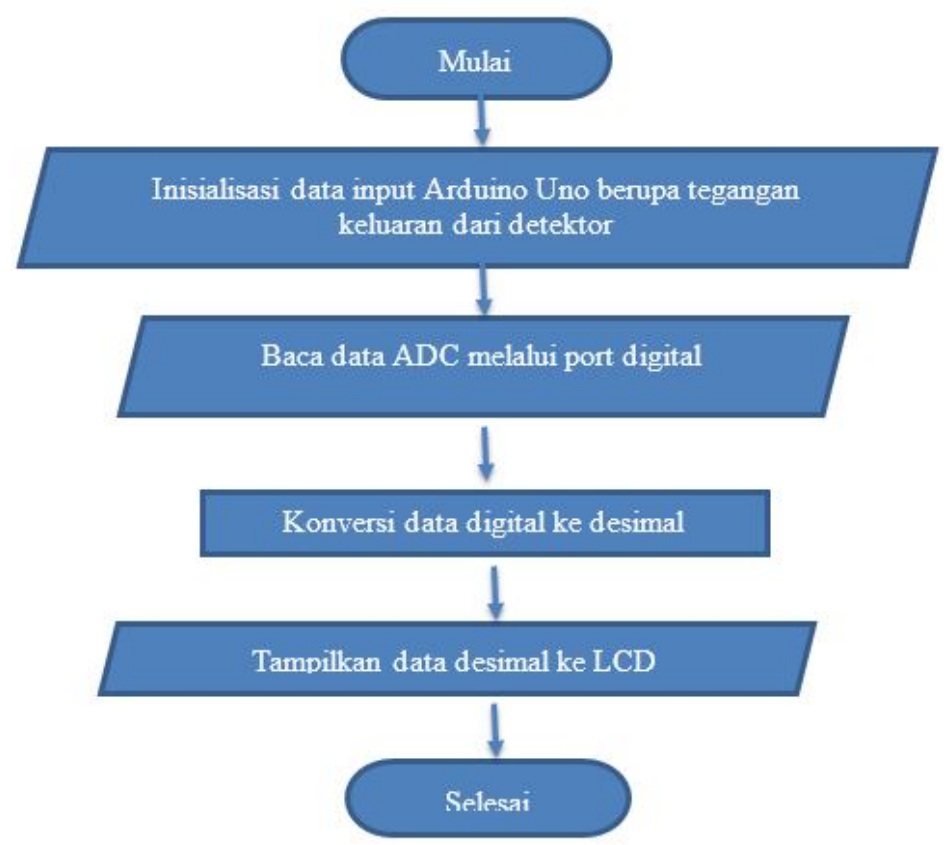

Gambar 3 Diagram alir alat ukur tingkat kekeruhan air

Data input yang dihubungkan dengan arduino uno yaitu tegangan keluaran yang dihasilkan oleh detektor. Nilai ADC dibaca oleh arduino uno melalui port digital. Arduino uno mengkonversi data digital ke desimal sesuai dengan program yang telah di-upload ke dalam arduino uno. Hasil konversi data ditampilkan melalui LCD.

\subsection{Perancangan Sistem Sensor}

Pada sistem sensor, fotodioda array diletakkan $90^{\circ}$ terhadap sumber cahaya. Hal ini dilakukan sesuai dengan metode nephelometry yang dipakai pada penelitian ini. Pengukuran tingkat kekeruhan zat cair dengan metode nephelemeter (sudut $90^{\circ}$ ) paling sensitif dibandingkan dengan sudut $45^{\circ}$ dan $0^{\circ}$ (metode turbidimeter) (Hendrizon, 2012).

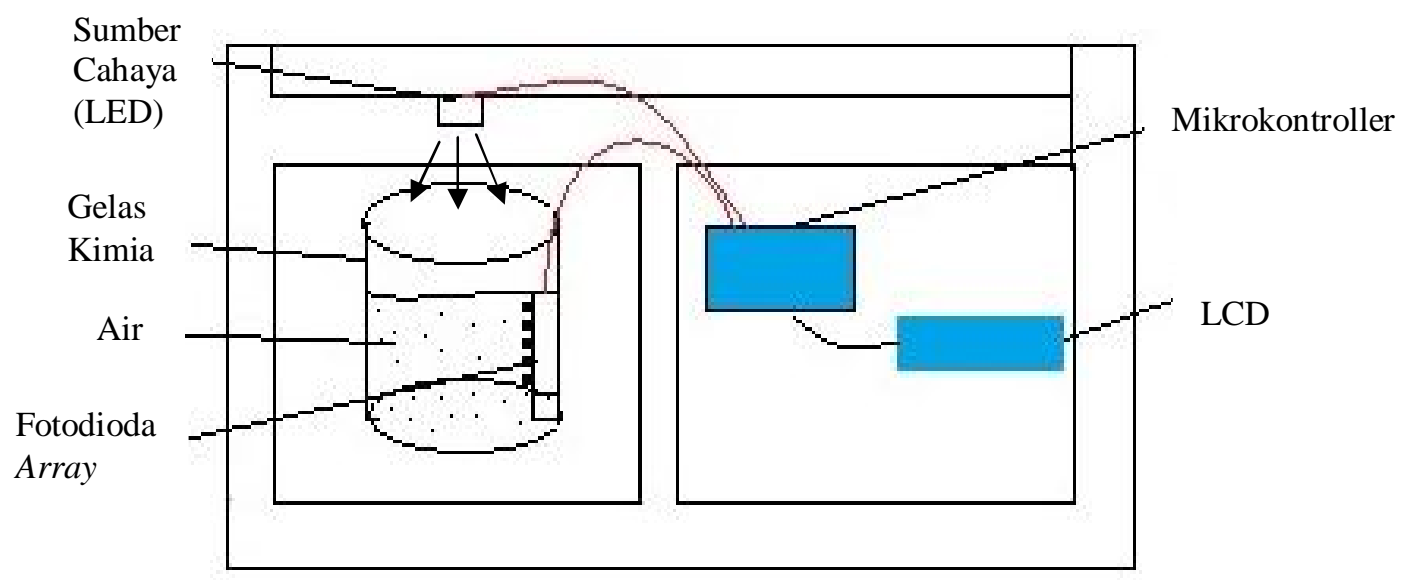

Gambar 4. Sistem sensor

Gambar 4 menunjukan sistem sensor yang dibuat. Tinggi dari fotodioda array yang dibuat yaitu $4,5 \mathrm{~cm}$ lalu diletakkan di dalam gelas kimia dengan posisi vertikal. LED 
ditembakkan ke arah sampel air. Partikel-partikel yang berada di dalam sampel air akan mengakibatkan hamburan cahaya. Hamburan cahaya yang terjadi dideteksi oleh fotodioda array. Pengukuran menggunakan fotodioda array bertujuan untuk memperluas jangkauan deteksi cahaya. Hasil yang didapatkan ditampilkan pada LCD.

\section{HASIL DAN DISKUSI}

\subsection{Hasil Perancangan Fotodioda Array}

Perancangan fotodioda dilakukan untuk melihat sensitivitas fotodioda yang disusun secara paralel. Fotodioda disusun sebanyak 2 buah, 3 buah, 4 buah, 5 buah, 6 buah, 7 buah, dan 8 buah. Rancangan yang memiliki nilai sensitivitas yang bagus digunakan sebagai fotodioda array untuk mendeteksi kekeruhan air. Hasil dari percobaan fotodioda array menunjukkan bahwa semakin banyak fotodioda yang digunakan maka nilai sensitivitasnya akan semakin bagus. Lima fotodioda diambil sebagai rancangan sensor yang digunakan pada penelitian ini karena memiliki nilai sensitivitas yang bagus. Lima buah fotodioda tersebut disusun secara paralel lalu diletakkan secara vertikal di dalam wadah tempat bahan uji. Fotodioda array digunakan agar titik pengukuran lebih dari satu sehingga alat yang dibuat lebih akurat.

\subsection{Hasil Pengujian Sistem Pengukuran Tingkat Kekeruhan Air}

Turbidimeter yang digunakan sebagai pembanding pada penelitian ini yaitu Turbidimeter 355T. Alat diuji di laboratorium Analisis Instrumen SMK SMTI Padang pada tanggal 20 Maret 2018. Larutan dibuat sebanyak 7 kali dengan tingkat kekeruhan berbeda. Larutan yang digunakan yaitu dengan melarutkan kopi dengan tingkat kekeruhan yang berbeda untuk mendapatkan tingkat kekeruhan yang berbeda. Kekeruhan dibuat menggunakan bubuk kopi. Larutan tersebut lalu diukur tingkat kekeruhannya dengan Turbidimeter 355T dan besar tegangan keluarannya menggunakan alat yang telah dirancang. Pada alat yang telah dirancang, volume air yang diukur yaitu $150 \mathrm{ml}$. Data perbandingan nilai kekeruhan dengan tegangan keluaran dapat dilihat pada Tabel 1.

Tabel 1 Hasil perbandingan nilai tingkat kekeruhan dengan tegangan keluaran

\begin{tabular}{cccc}
\hline No & Jenis Larutan & $\begin{array}{c}\text { Nilai tingkat kekeruhan } \\
\text { berdasarkan Turbidimeter } \\
\text { 355T (NTU) }\end{array}$ & $\begin{array}{c}\text { Tegangan } \\
\text { Keluaran (mV) }\end{array}$ \\
\hline 1 & Larutan 1 & 1,28 & 4600 \\
2 & Larutan 2 & 50,62 & 4630 \\
3 & Larutan 3 & 63,52 & 4640 \\
4 & Larutan 4 & 81,37 & 4680 \\
5 & Larutan 5 & 103,2 & 4690 \\
6 & Larutan 6 & 123,7 & 4700 \\
7 & Larutan 7 & 159,3 & 4710 \\
\hline
\end{tabular}

Hasil data pengukuran yang telah didapat ini lalu ditentukan fungsi transfer dan nilai regresinya menggunakan grafik. Gambar 5 menunjukkan bahwa fungsi transfer yaitu y = $0,7673+4600,4$. Fungsi transfer ini yang nantinya di-upload pada Arduino Uno. Koefisien determinasi yang didapatkan yaitu 0,9257. Tingkat sensitivitas alat ukur yaitu sebesar 0,7673 $\mathrm{mV} / \mathrm{NTU}$, sehingga setiap kenaikan tingkat kekeruhan 1 NTU maka menaikkan tegangan sebesar $0,7673 \mathrm{mV}$. 


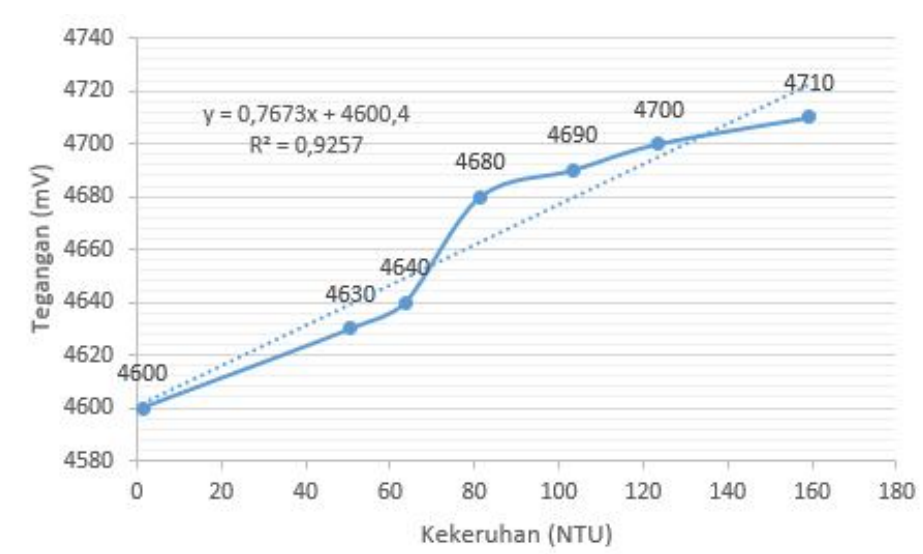

Gambar 5 Grafik antara tingkat kekeruhan air dan tegangan keluaran

Program di-upload pada Arduino Uno, alat yang telah dirancang dapat mengukur tingkat kekeruhan air. Hasil yang didapatkan lalu dibandingkan dengan tingkat kekeruhan air berdasarkan Turbidimeter 355T. Tabel 2 menunjukkan nilai kekeruhan air dengan Turbidimeter $355 \mathrm{~T}$ dan kekeruhan air dengan alat yang dirancang.

Tabel 2 Hasil pengujian alat terhadap alat acuan

\begin{tabular}{cccc}
\hline Jenis & \multicolumn{2}{c}{ Kekeruhan (NTU) } & \multirow{2}{*}{ \% Kesalahan } \\
\cline { 2 - 3 } Larutan & $\begin{array}{c}\text { TURB } \\
\text { 355T }\end{array}$ & $\begin{array}{c}\text { Alat yang } \\
\text { dirancang }\end{array}$ & \\
\hline Larutan 1 & 0,33 & $-1,324$ & Tidak Digunakan \\
Larutan 2 & 16,8 & 17,57 & 4,58 \\
Larutan 3 & 25,72 & 23,94 & 6,92 \\
Larutan 4 & 63,45 & 62,1681 & 2,02 \\
Larutan 5 & 75,21 & 74,908 & 0,40 \\
Larutan 6 & 128 & 125,861 & 1,67 \\
Larutan 7 & 193,8 & 189,551 & 2,19 \\
Larutan 8 & 220,1 & 132,239 & Tidak Digunakan \\
Larutan 9 & 239,9 & 87,6444 & Tidak Digunakan \\
Larutan 10 & 262,4 & $-27,025$ & Tidak Digunakan \\
\hline
\end{tabular}

Tabel 2 menunjukkan bahwa tingkat kekeruhan air dapat diukur dalam rentang 17,57 NTU sampai 189,551 NTU. Pengukuran di luar rentang tersebut menghasilkan data yang tidak lagi akurat. Pengukuran dalam rentang 17,57 NTU sampai 189,551 NTU memiliki kesalahan relatif maksimum sebesar 6,920 \% dan kesalahan relatif rata-rata yaitu sebesar 2,964 \%.

\section{KESIMPULAN}

Hasil penelitian menggunakan fotodiodda array dengan susunan 5 buah fotodioda secara paralel mampu mengukur tingkat kekeruhan air pada rentang 17,57 NTU sampai 189,551 NTU. Sensitivitas alat ukur yaitu sebesar $0,7673 \mathrm{mV} / \mathrm{NTU}$, setiap kenaikan tingkat kekeruhan 1 NTU maka tegangan bertambah sebesar $0,7673 \mathrm{mV}$ dengan error rata-rata alat ukur tingkat kekeruhan air yang telah dirancang sebesar 2,964\%.

\section{DAFTAR PUSTAKA}

Hendrizon, Y., dan Wildian, "Rancang Bangun Alat Ukur Kekeruhan Zat Cair Berbasis MikrokontrolerAT89s51 Menggunakan Sensor Fototransistor dan Penampil LCD”, Jurnal Fisika Unand, 1[1], hal 6-11 (2012).

Internasional Standards Organization, Water Quality - Determination of Turbidity, ISO 7027, (Geneva, Switzerland, 1999).

Lambrou, T.P., Anastasiou, C.C., dan Panayiotou, C.G., "A Nephelometric Turbidity System for Monitoring Residential Drinking Water Quality", (Frederick University Cyprus, Nicosia, 2008), hal. 43-45. 
Maemunnur, A.F. Wiranto, G. dan Waslaluddin, "Rancang Bangun Sistem Alat Ukur Turbidity Untuk Analisis Kualitas Air Berbasis Arduino Uno", Fibusi /JoF, No. 1, hal 1-4 (2016).

Nuzula, N.I. dan Endarko, "Rancang Bangun Alat Ukur kekeruhan Air Berbasis Mikrokontroler", Berkala Fisika, 6[4], hal. 111-118 (2013).

Paramytha, N., dan Kasim, A. "Pendeteksi Kejernihan Air Dengan Menggunakan Indikator LED Dan LCD”, Proceedings Seminar Nasional Teknik Elektro (FORTEI 2016), (Teknik Elektro Universitas Diponegoro, Semarang, Indonesia, 2016), hal. 36-40.

Permenkes. Syarat-syarat Dan Pengawasan Kualitas Air, Nomor : 416/MEN.KES/PER/IX/1990 (3 september 1990).

Romano, P.J., Dilts, M.J., dan Makarovsky, Y.I., "Petiside Analysis Using HPLC with PDA/MS Detecion”, (Waters Corporation, St. Milford. U.S.A, 2010).

Siltri, D.M. Yohandri, dan Kamus, Z., "Pembuatan Alat Ukur Salinitas dan Kekeruhan Air Menggunakan Sensor Elektroda dan LDR”, Jurnal Saintek, 7[2], hal. 126-139 (2015). 